\title{
Diagnostic Reference Level in Lumbar Radiography in Abidjan, Côte d'ivoire
}

\author{
Issa Konate ${ }^{1}$, Monnehan Georges Alain ${ }^{2}$, Gogon Bogbe Douo L.H $\mathrm{H}^{3}$, \\ Kezo Ponaho Claude ${ }^{4}$, Dali Tekpo Paul ${ }^{5}$, Koua Aka Antonin ${ }^{6}$, \\ Koudou Djagouri ${ }^{7}$ \\ ${ }^{1}$ Laboratory of Nuclear Physics and Radioprotection, University Felix Houphouet Boigny of Côte d'Ivoire \\ ${ }^{2}$ Laboratory of Nuclear Physics and Radioprotection, University Felix Houphouet Boigny of Côte d'Ivoire \\ ${ }^{3}$ Laboratory of Nuclear Physics and Radioprotection, University Felix Houphouet Boigny of Côte d'Ivoire \\ ${ }^{4}$ Laboratory of Nuclear Physics and Radioprotection, University Felix Houphouet Boigny of Côte d'Ivoire \\ ${ }^{5}$ Laboratory of Nuclear Physics and Radioprotection, University Felix Houphouet Boigny of Côte d'Ivoire
}

\begin{abstract}
-
This study aims to determine the diagnostic reference levels (DRLs) for posterior-anterior lumbar and profile lumbar examinations in order to optimize the entrance dose (De) and the dose area product $(D A P)$ of patient in Abidjan. A total of 240 patients undergoing conventional radiology in four hospitals of the city were considered. The device used to measure De and DAP values is a DAP-meter, model Diamentor M4 KDK and of type 11017. The DRLs in terms of De and DAP values were determined by applying the 75th percentile method. These values were compared to DRLs values obtained in other countries and to those recommended by international institutions. The values of De measured are encouraging, however for the DAP; many efforts are needed to be made to reduce the DRLs values
\end{abstract}

Keyword: Conventional radiology, DAP-meter, De, DAP, DRLs

Date of Submission: 09 February 2017

$\longrightarrow$ Date of Accepted: 25 February 2017

\section{INTRODUCTION}

The establishment of diagnostic reference levels (DRLs) has recently become one of the essential questions in the management of patient dose received in radiodiagnostic and conventional radiology. Therefore, there is an increasing need of harmonization of practices and doses including a normalization of procedures and an optimization of parameters influencing the dose delivered to patients. Many scientific meetings have shown a great interest concerning the diagnostic reference levels such as workshops in Italia in 1993 [1], Luxembourg in 1997 [2], the IAEA conference in Malaga in 2001 [3]. Some decisions were also taken by states like those of European community through the Directive 97/43 [4] which is a part of the International Commission of Radiological Protection publication No 70 to establish the DRLs. In Côte d'Ivoire also, a preliminary study was carried out by G. A. Monnehan et al [5]. This study provided DRLs values in terms of De in three radiological centres for thoracic and ASP examinations.

This study aims to deepen the work already realized by determining the DRLs in terms of De and DAP in four hospitals in Abidjan, for lumbar examination of 240 patients in conventional radiology. The obtained values were analysed and discussed by comparing themselves. These values were then compared to those obtained in other countries and international institutions. The final objective is to provide to conventional radiology practicians some reference dose values in order to ensure the management of the doses delivered and the efficient control of the exposure of patients in Côte d'Ivoire.

\subsection{Working method}

\section{MATERIALS AND METHODS}

We selected four (4) conventional radiological rooms corresponding to the four (4) public hospitals which are: Cocody Teaching Hospital Centre (H1), Yopougon Teaching Hospital Centre (H2), Military Hospital of Abidjan (H3) and Cardiology Institute of Abidjan (H4) These centres respect the Ivorian norms such as a surface of at least $25 \mathrm{~m}^{2}$, a height under roof of at least $3.50 \mathrm{~m} \mathrm{[6]} \mathrm{and} \mathrm{having} \mathrm{been} \mathrm{inspected} \mathrm{and} \mathrm{controlled} \mathrm{for} \mathrm{quality}$ control purpose. In each radiological room, we interested on the radiology of facial and profile lumbar which are the most undergone examinations after the thoracic one. For each examination, thirty (30) patients were taken based on the Radiation Protection Institute and Nuclear Safety (IRSN) recommendations [7], all of more than 18 years old. Only were considered the patients who were able stand up. Patients who were lied down on bed or sat were excluded. 


\subsection{Data collection}

Some mails were sent to the Directors of the four diagnostic facilities and our study started after their agreements.

The data were collected during three months, June, July, and August 2015 in the four radiological rooms selected according the above criteria. The data collection consisted on recording the name of the facility, the name of the patient, the type of examination, the last date of inspection and quality control. Also, for each device we recorded the date of installation, the mark, the model and the additional filtering. For each of the 30 patients, we recorded the age, the size, the masse, and the thickness of the thoracic. The distance source-patient and the radiological parameters (voltage in $\mathrm{kV}$ and power in $\mathrm{mAs}$ ) were also recorded.

The patient's DAP and the dose in air (Dair) were measured with a DAP-meter. These values were recorded for each diagnostic room.

\subsection{Materials}

In each conventional radiologic room the materials found are high voltage generator, X-ray machine, a desk to fix the $\mathrm{kV}$ and $\mathrm{mAs}$, an examination table, detectors and shielding equipment to protect the technicians. For this study, we used a DAP-meter (Diamentor M4-KDK and of type 11017 made by the German enterprise PTW). This device was offered by IAEA to Côte d'Ivoire and previously calibrated at PTW-Freiburg with mGy and Gy. $\mathrm{cm}^{2}$ values. It's composed of an ionizing chamber of mark Diamentor and an electrometer (DAP-meter reader).

The ionizing chamber is placed at the output of the X-ray tube at the collimator side. The ionizing chamber is the main tool used to measure the patient dose. It's a plastic enceinte containing a gas (air) and two electrodes between which is established a potential difference. When the X-rays traverse the enceinte, they ionize the gas and a power which the intensity is proportional to the X-ray flow, is established in the ionizing chamber. This power is conducted to the electrometer which converts it both into Dair and DAP [8].

Then with the 75th percentile statistical method [9] proposed by the European Community, the diagnostic reference levels in terms of De and DAP were determined. The De was calculated by the following equation:

De $=$ Dair x BSF

Where: Dair is the dose in air,

$\mathrm{BSF}$ is the backscatter factor equal to 1.35 for a voltage varying from 60 to $80 \mathrm{kV}$ or 1.5 if the voltage is above $80 \mathrm{kV}[10]$.

\section{RESULTS AND DISCUSSIONS}

This part presents the results of our work and the appropriate discussion.

\subsection{Facial lumbar spine examination}

\subsubsection{Radiological and morphological parameters}

Some radiological and morphological parameters such as $\mathrm{kV}, \mathrm{mAs}$, distance focus-film (DFF), mass, size, thickness of the patient can influence the dose delivered to patient during the diagnostic examination. Therefore, it's necessary to measure these parameters in each radiological room. The radiological and morphological parameters measured in this work during the lumbar spine of face examination are presented in Table 1.

Table 1: Radiological and patient morphological parameters for facial lumbar spine examination

\begin{tabular}{|l|l|l|l|l|l|l|l|l|}
\hline \multirow{2}{*}{$\begin{array}{l}\text { Diagnostic } \\
\text { centre }\end{array}$} & \multicolumn{2}{l|}{$\mathrm{kV}$} & $\mathrm{mAs}$ & Av. Mass (kg) & Av. Size (cm) & Av. Thickness & DFF (cm) \\
\cline { 2 - 9 } & Range & Av. kV & Range & Av. mAs & & & & \\
H1 & $50-95$ & 83.80 & $32-87$ & 53.53 & 74.15 & 165.86 & 23.83 & 100 \\
H2 & $60-90$ & 70.56 & $36-90$ & 53.70 & 74.77 & 160.26 & 25.16 & 100 \\
H3 & $70-95$ & 80.16 & $50-100$ & 74.46 & 66.93 & 170.70 & 23.60 & 76.40 \\
H4 & $80-96$ & 87.90 & $27-40$ & 31.42 & 75.86 & 160.30 & 24.78 & 100 \\
\hline
\end{tabular}

Av: average value.

According to Table 1, for the facial lumbar spine examination, the highest average value of $\mathrm{kV}$ of $87.90 \mathrm{kV}$ is measured in $\mathrm{H} 4$ and the lowest average $\mathrm{kV}$ of $70.56 \mathrm{kV}$ is found in $\mathrm{H} 2$.

The highest average value of mAs of $74.46 \mathrm{mAs}$ is recorded in $\mathrm{H} 3$ whereas the lowest average of $31.42 \mathrm{mAs}$ is recorded in $\mathrm{H} 4$

Table 1 shows that the highest values of patient mass, size, and thickness are recorded respectively in $\mathrm{H} 4, \mathrm{H} 3$, and H2. It shows also that in every diagnostic room, the distance focus-film (DFF) used is $100 \mathrm{~cm}$ except for the $\mathrm{H} 3$ where the DFF is $76.40 \mathrm{~cm}$.

After recording these radiological and morphological parameters, the diagnostic reference levels were determined for each centre. 


\subsubsection{Diagnostic reference level for facial lumbar spine examination of the centres}

The DRLs for the lumbar spine of face examination in terms of entrance dose (De) and dose area product (DAP) were calculated for every diagnostic centre using the above equation (1). The results of this calculation are presented in Table 2.

Table 2: DRL values for lumbar spine of face examination of the centres

\begin{tabular}{|l|l|l|}
\hline \multirow{2}{*}{$\begin{array}{l}\text { Diagnostic } \\
\text { centre }\end{array}$} & \multicolumn{2}{|l|}{ Diagnostic reference level } \\
\cline { 2 - 3 } H1 & De $(\mathrm{mGy})$ & DAP $\left(\mathrm{Gy} . \mathrm{cm}^{2}\right)$ \\
$\mathrm{H} 2$ & 5.07 & 1.87 \\
$\mathrm{H} 3$ & 3.83 & 2.52 \\
$\mathrm{H} 4$ & 11.70 & 13.71 \\
\hline
\end{tabular}

The above table presents the lowest values of De and DAP respectively of $3.25 \mathrm{mGy}$ and $1.54 \mathrm{~Gy} . \mathrm{cm}^{2}$ measured in H4. Whereas the highest values of De and DAP respectively of $11.70 \mathrm{mGy}$ and $13.71 \mathrm{~Gy} . \mathrm{cm}^{2}$ were measured in $\mathrm{H} 3$ centre.

The lowest value of DRLs in H4 centre could be justified by the lowest value of mAs recorded in this centre. The value of $\mathrm{kV}$ also recorded is suitable according to French Society of Radiology recommendation. In fact according to French Society of Radiology the recommended values of $\mathrm{kV}$ and $\mathrm{mAs}$ necessary to optimize patient entrance dose in facial lumbar spine examination should range respectively from 65 to $80 \mathrm{kV}$ and from 30 to $70 \mathrm{mAs}$ with a tendency to further reduce the mAs and increase the $\mathrm{kV}$ [4]. Otherwise, the highest dose observed in $\mathrm{H} 3$ centre could be explained by the recorded value of mAs of $76.46 \mathrm{mAs}$ higher than the recommended value and also by the short distance between the focus and the film. The recommended DFF value ranges from $100 \mathrm{~cm}$ to $120 \mathrm{~cm}$. The difference between the De values measured in the different centres could be justified by many factors such as difference in the radiological and morphological parameters recorded but in the quality of the devices used.

For the DAP values measured in the centres, the lowest value of $1.54 \mathrm{~Gy} \mathrm{~cm}^{2}$ was determined in $\mathrm{H} 4$ while the highest value was found in $\mathrm{H} 3$ centre. The difference between the DAP values in the centres might be due to a failure in the X-ray beam adjustment.

\subsection{Profile lumbar spine examination}

\subsubsection{Radiological and morphological parameters}

The radiological and morphological parameters recorded in each diagnostic centre for this examination are presented in Table 3.

Table 3: Radiological and patient morphological parameters for profile lumbar spine examination

\begin{tabular}{|c|c|c|c|c|c|c|c|c|}
\hline \multirow{2}{*}{$\begin{array}{l}\text { Diagnostic } \\
\text { centre }\end{array}$} & \multicolumn{2}{|l|}{$\mathrm{kV}$} & \multicolumn{2}{|l|}{$\mathrm{mAs}$} & \multirow{2}{*}{$\begin{array}{l}\text { Mass (kg) } \\
\text { Av. }\end{array}$} & \multirow{2}{*}{$\begin{array}{l}\text { Size }(\mathrm{cm}) \\
\text { Av. }\end{array}$} & \multirow{2}{*}{$\begin{array}{l}\text { Thickness (cm) } \\
\text { Av. }\end{array}$} & \multirow[t]{2}{*}{ DFF $(\mathrm{cm})$} \\
\hline & Range & Av. & Range & Av. & & & & \\
\hline H1 & $85-118$ & 100.23 & $50-200$ & 100.36 & 77.37 & 165.90 & 27.65 & 100 \\
\hline $\mathrm{H} 2$ & $70-76$ & 72.06 & $80-200$ & 139.66 & 77.21 & 160.43 & 29.13 & 100 \\
\hline $\mathrm{H} 3$ & $70-98$ & 85.36 & $50-200$ & 145.66 & 67.06 & 169.96 & 23.60 & 77 \\
\hline $\mathrm{H} 4$ & $86-106$ & 96.83 & $30-60$ & 36.28 & 74.96 & 165.13 & 29.68 & 100 \\
\hline
\end{tabular}

Av: Average value.

For the profile lumbar spine examination, the highest average value of $\mathrm{kV}$ of $100.23 \mathrm{kV}$ is recorded in $\mathrm{H} 1$ and the lowest average of $72.06 \mathrm{kV}$ is in $\mathrm{H} 2$. The highest average value of mAs of $145.66 \mathrm{mAs}$ is recorded in $\mathrm{H} 3$ whereas the lowest average of $\mathrm{mAs}$ of $36.28 \mathrm{mAs}$ is recorded in $\mathrm{H} 4$.

The lowest values of mass, size, and thickness are respectively measured in $\mathrm{H} 3, \mathrm{H} 4$, and $\mathrm{H} 3$. Whereas the highest values are recorded respectively in $\mathrm{H} 1$ and $\mathrm{H} 2, \mathrm{H} 3$, and $\mathrm{H} 3$ centres. The distance focus-film used for the examination is $100 \mathrm{~cm}$ except for $\mathrm{H} 3$ where it is $77 \mathrm{~cm}$. The De and DAP values also were calculated for every centre.

\subsubsection{Diagnostic reference level for profile lumbar spine examination of the centres}

The DRLs in terms of entrance dose (De) and dose area product (DAP) calculated are presented in Table 4.

Table 4: DRL values for profile lumbar spine examination of the centres.

\begin{tabular}{|l|l|l|}
\hline \multirow{2}{*}{$\begin{array}{l}\text { Diagnostic } \\
\text { centre }\end{array}$} & Diagnostic reference levels \\
\cline { 2 - 3 } & De $(\mathrm{mGy})$ & DAP $\left(\mathrm{Gy} . \mathrm{cm}^{2}\right)$ \\
\hline $\mathrm{H} 1$ & 9.63 & 4.98 \\
$\mathrm{H} 2$ & 8.78 & 7.96 \\
$\mathrm{H} 3$ & 15.83 & 28.22 \\
$\mathrm{H} 4$ & 4.35 & 1.87 \\
\hline
\end{tabular}


According to Table 4, the lowest value of De for profile lumbar spine examination is measured in $\mathrm{H} 4$ centre. The highest value of De in $\mathrm{H} 3$ may be explained by the high average mAs value recorded in the centre during the examination (See Table 3). However, the DRL in term of De of $15.83 \mathrm{mGy}$ measured in $\mathrm{H} 3$ centre is lower than $25 \mathrm{mGy}$, the reference value of De established by IRSN [7].

For the DAP, the lowest value is measured in $\mathrm{H} 4$ and the highest value is found in $\mathrm{H} 3$ centre. This highest value of DAP in $\mathrm{H} 3$ is three time higher than the IRSN reference value of $8 \mathrm{~Gy} . \mathrm{cm}^{2}$ [7]. This difference might be due to a failure in the $\mathrm{X}$-ray beam adjustment in $\mathrm{H} 3$ centre.

\subsection{Diagnostic reference levels in Abidjan}

The DRLs of the public diagnostic centres in Abidjan is defined as the overall average of $\mathrm{kV}, \mathrm{mAs}$, De, and DAP values of the four public centres studied. These values are the arithmetical averages of the above mentioned quantities [11] and the DRLs in terms of De and DAP were determined by 75th percentile method.

The DRL values for the lumbar spine examination in Abidjan corresponding to the average values of $\mathrm{kV}$ and mAs are presented in Table 5.

Table 5: Diagnostic reference levels (DRLs) for lumbar spine examinations in Abidjan

\begin{tabular}{|l|l|l|l|l|l|l|}
\hline \multirow{2}{*}{ Examination } & $\mathbf{k V}$ & \multicolumn{2}{l|}{ mAs } & DRLs \\
\cline { 2 - 7 } & Average & Range & Average & Range & De $(\mathrm{mGy})$ & DAP(Gy.cm $\left.{ }^{2}\right)$ \\
\hline Facial lumbar & 80.6 & $50-96$ & 53.28 & $26.5-100$ & 5.56 & 5.66 \\
\hline Profile lumbar & 88.6 & $70-118$ & 105.5 & $30-200$ & 11.54 & 11.93 \\
\hline
\end{tabular}

The DRL values obtained in Abidjan were compared to some DRLs values measured in other countries over the world and the comparison is presented in Table 6 below.

Table 6: Comparison of the DRL values obtained in the present work with other works

\begin{tabular}{|l|l|l|l|l|l|l|l|l|l|l|}
\hline \multicolumn{2}{|l|}{ Lumbar Examination } & \multicolumn{2}{l|}{ Diagnostic reference levels } \\
\cline { 3 - 12 } \multicolumn{2}{c|}{} & $\begin{array}{l}\text { Present } \\
\text { study }\end{array}$ & $\begin{array}{l}\text { Iran } \\
{[12]}\end{array}$ & $\begin{array}{l}\text { UK } \\
{[13]}\end{array}$ & $\begin{array}{l}\text { Soudan } \\
{[15]}\end{array}$ & $\begin{array}{l}\text { Serbia } \\
{[14]}\end{array}$ & $\begin{array}{l}\text { France } \\
{[7]}\end{array}$ & $\begin{array}{l}\text { Switzer land } \\
{[16]}\end{array}$ & $\begin{array}{l}\text { Ghana } \\
{[14]}\end{array}$ & $\begin{array}{l}\text { Tanzania } \\
{[14]}\end{array}$ \\
\hline Facial & De (mGy) & 5.56 & 4.43 & 5.70 & 1.63 & 10.05 & 10 & 7 & 8.3 & 2.1 \\
\cline { 2 - 12 } & $\begin{array}{l}\text { PDS } \\
\left(\mathrm{Gy} . \mathrm{cm}^{2}\right)\end{array}$ & 5.66 & - & 1.5 & - & - & 4.5 & 2.35 & - & - \\
\hline Profile & De (mGy) & 11.54 & 4.8 & 10 & 3.29 & 14.72 & 25 & 10 & 14.4 & 4.7 \\
\cline { 2 - 11 } & $\begin{array}{l}\text { PDS } \\
\left(\mathrm{Gy} . \mathrm{cm}^{2}\right)\end{array}$ & 11.92 & - & 2.50 & - & - & 8 & 4.15 & - & - \\
\hline
\end{tabular}

According to Table 6, the De value of $5.56 \mathrm{mGy}$ obtained for the facial lumbar spine examination in Abidjan is lower than the values obtained in other countries such as France, Switzerland, Serbia, UK, and Ghana. This could be due to the use of average value of $\mathrm{kV}$ of $80.6 \mathrm{kV}$ and mAs value of $53.28 \mathrm{mAs}$ ranging in the SFR recommended values of $\mathrm{kV}$ and $\mathrm{mAs}$ respectively of $(65-80 \mathrm{kV})$ and $(30-70 \mathrm{mAs})$. However this value is higher than those obtained in other countries such as Iran, Tanzania, Soudan, etc. Therefore, we could further reduce the De in our diagnostic centres by reducing the mAs and keeping the value in SFR recommended range. The DRL value in term of DAP in Abidjan for the facial lumbar examination is higher than the obtained values in France, UK, and Switzerland whereas the De value in Abidjan was lower. Therefore, many efforts might be made by practicians to reduce the DAP value by using the diaphragm to reduce the $\mathrm{X}$-ray beam.

Considering the profile lumbar examination, the De value of $11.54 \mathrm{mGy}$ obtained in Abidjan is lower than the values obtained in France, Serbia, Ghana, etc. This result could be justified by the average values of kV (88.6 $\mathrm{kV}$ ) and $\mathrm{mAs}(105.5 \mathrm{mAs}$ ) ranging in the recommended values established by French society of radiology (SFR) respectively of $(80-100 \mathrm{kV})$ and $(70-150 \mathrm{mAs})$. However our measured De value is higher than the De values obtained in UK, Switzerland, Soudan, Iran, etc.

The DRLs in De can be reduced by using the maximum values of the recommended $\mathrm{kV}$ and $\mathrm{mAs}$.

For this profile lumbar examination, the DAP value is higher than the DAP values measured in many countries such as France. Form Table 6, we notice a low value of De and a high value of DAP in Abidjan. Therefore, this high value of DAP obtained could be justified by the failure in X-ray beam focusing. Therefore, it's important for medical diagnostic practicians to focus on the use of diaphragm during the examinations.

\section{CONCLUSION}

At the end of this study, our objective of determining the reference diagnostic levels for lumbar examinations in Abidjan (Côte d'Ivoire) is reached. For all the diagnostic centres, the values of the entrance dose (De) and the dose area product (DAP) were measured. A De value of $5.56 \mathrm{mGy}$ and a DAP value of $5.66 \mathrm{~Gy} . \mathrm{cm}^{2}$ were found for the facial lumbar spine examination. However for the profile lumbar examination the DRLs values in terms of De and DAP were respectively $11.54 \mathrm{mGy}$ and $11.93 \mathrm{~Gy} . \mathrm{cm}^{2}$. 
The DRL values in term of De obtained in Abidjan through this study are found to be acceptable because they are lower than the De values obtained in many countries. However the DRLs values in term of DAP value are higher compared to the DAP values measured in many country. Therefore the efforts such as the use of diaphragm during the examinations, the use of the recommended $\mathrm{kV}$ and $\mathrm{mAs}$ are needed by the diagnostic practicians to optimize the De and DAP values.

This study carried out after the one done by Monnehan et al in 2009, should be pursued in every diagnostic centre in the country in order to establish a general diagnostic reference level of the country comparable to the DRL recommended by IAEA and IRSN.

\section{ACKNOWLEDGEMENTS}

The authors of this work thank the Director of National Laboratory of Public Health (LNPS) and all the staff of the service against ionizing radiation for the use of their facilities and their availability. They also thank the Directors of the all the diagnostic centres for the cooperation.

\section{REFERENCES}

[1]. Sinnaeve, J. Quality control and radiation protection of the patient in diagnostic radiology and nuclear medicine. Proceeding of a workshop held in Grado, Italy. 29 September - 1 October 1993. Radiat. Prot. Dosim. 57 (1-4), 1-2, 1995

[2]. Lahure J., Kaul, A. and Sinnaeve, J. Reference doses and quality in medical imaging, Proceedings of a workshop held in Luxembourg, 23-25 october 1997. Radiat. Prot. Dosim. 80 (1-3), 1-5, 1998.

[3]. International Atomic Energy Agency. Proceedings of the international conference on the radiological protection in diagnostic and interventional radiology, Malaga 26-30 March 2001. IAEA C\&S papers series 7/P, Vienna 2001.

[4]. Societe Francaise de Radiology (SFR) OPRI-SFR. Procédures radiologiques, Mars 2001

[5]. G. A. Monnehan, K. J. Anouan, D. P. Onoma, K. B. Yao, L. D. Kouadio, A. A. Koua et P. A. T. Dali. Détermination des niveaux de référence diagnostiques en Côte d'Ivoire : cas de la radiographie du thorax de face et de l'abdomen sans préparation (ASP) de face chez l'adulte dans le district d'Abidjan et dans la région du Sud Comoé. Rev. Ivoir sci. Technol., 14, 2009.

[6]. Journal officiel de la République de Côte d'Ivoire du 9 juillet 1968, Article 4D 497 du Décret nº7-321 du 21 Juillet 1967.

[7]. Analyse des données relatives à la mise à jour des niveaux de référence diagnostiques en radiologie et en médecine nucléaire bilan 2011-2012. Pole radioprotection, environnement, déchets et crise. IRSN Rapport PRP-HOM/2014-9

[8]. User manual diasoft version 5.2. D154.131.O/7 2004-03 Md /Hn

[9]. T. Piketty, « income inequality in France, 1901-1988». Journal of political economy, vol.111. $n^{\circ} 5$, P. 1004-1042, 2003.

[10]. Hervé LECLET. La métrologie des niveaux de doses dans les pratiques radiodiagnostiques. http://www.santopta.fr/wpcontent/uploads/2011/12/La-m\%C3\%A9trologie-des-niveaux-de-doses-dans-les-pratiques-radiodiagnostiques.pdf

[11]. Fabrice Mazerolle. «Moyenne arithmétique ». https://fr.wikipedia.org/wiki/Moyenne_arithmétique, 2012.

[12]. Asadinezhad M, Toosi MTB. Doses to patients in some routine diagnostic X-ray examinations in Iran: Proposed the first Iranian diagnostic Reference Levels. Radiation Protection Dosimetry, vol. 132. No. 4: pp. 409-414. 2008.

[13]. Hart D, Hillier MC, and Shrimpton P C. HPA-CRCE-034-Doses to patients from Radiographic and fluoroscopic X-ray imaging procedures in the UK-2010. Review June 2012.

[14]. Muhogora WE, AhAlmosabihi A, Alsuwaidi J, Beganovic A, Ciraj- Bjelac O, Shandorf C, Rehani M J, Mukwada G, Rouzitalab J., Patient doses in radiographic examinations in 12 countries in Asia, Africa, and Eastern Europe: Initial results from IAEA projects, Am. Journal of Roentgenol, Vol 190, 1453-1461, 2008.

[15]. Suliman II, Abbas N, Habbani F I., Entrance surface doses to patients undergoing selected diagnostic X-ray examinations in Sudan. Radiation protection Dosimetry 123, 209-214, 2007

[16]. Office fédérale de la santé publique. Directive R-06-04. Niveaux de référence diagnostiques (NRD) en radiologie par projection, Berne, Suisse, 2011. Available on http://www.bag.admin.ch/themen/stralung/10463/10958/index.html ?lang=fr

\section{Biographies and Photographs}

\section{ISSA Konate}

Laboratory of Nuclear Physics and Radioprotection, PhD student at University Felix Houphouet Boigny of Côte d'Ivoire. K_issa66@yahoo.fr

\section{MONNEHAN Georges Alain}

Professor, Lecturer and Researcher in Department of Physics, University F.H.B of Côte d'Ivoire

Director of the Laboratory of Nuclear Physics and Radioprotection, University F.H.B of Côte d'Ivoire.

Assistant Director of the Department of Protection against Ionizing Radiation of the National Laboratory of Public Health, monnehan_alain@yahoo.fr

\section{GOGON Bogbe Douo L.H}

Doctorate of physics, Assistant Lecturer and researcher in Department of Physics, University F.H.B of Côte d'Ivoire ghuberson@hotmail.com

\section{KOUA Aka Antonin}

Professor, Lecturer and Researcher in Department of Physics, University F.H.B of Côte d'Ivoire antoninkoua@yahoo.fr

\section{KEZO Ponaho Claude}

MPhil in Nuclear Sciences and Technology, University of Ghana, Legon. Currently, PhD at University F.H.B of Côte d'Ivoire, ponaho04@yahoo.fr

DALI Tekpo Paul

Doctorate of physics, Lecturer and Researcher in Department of Physics, University F.H.B of Côte d'Ivoire paultekpo@yahoo.fr

KOUDOU Djagouri

Doctorate of physics, Lecturer and Researcher in Department of Physics, Ecole Normale Superieure.

djagourikoudou@yahoo.fr

Research Interests: Environmental Sciences, Radiation protection, and Fundamental Physics. 